\title{
A Modification of Infant Warmer with Monitoring of Oxygen Saturation, Heart Rate, and Skin Temperature
}

\author{
M Syahrul Azam Nampira' ${ }^{1}$, Abd. Kholiq ${ }^{1}$, and Lamidi ${ }^{1}$ \\ ${ }^{1}$ Department of Electromedical Engineering Poltekkes Kemenkes, Surabaya, Jl. Pucang Jajar Timur No. 10, Surabaya, 60282, Indonesia. \\ Corresponding Author: Abd. Kholiq (kawulloh@gmail.com)
}

\begin{abstract}
Full term and premature babies have decreased body temperature by $0.1^{\circ} \mathrm{C}-0.3{ }^{\circ} \mathrm{C}$ per minute, infant warmer was developed to provide the effect of heat on the baby as the temperature in the mother's uterus. The purpose of this study is to modify the infant warmer tool by adding parameters $\mathrm{SpO}_{2}$, $\mathrm{BPM}$, and skin sensors. The contribution of this research is that the $\mathrm{SpO}_{2}, \mathrm{BPM}$, and skin sensor monitoring systems are very helpful in the therapeutic and healing process using infant warmers. The use of the right sensor and has good quality will produce results and a small error value so it does not exceed the maximum value that is tolerated. The MAX 30100 sensor can detect oxygen saturation in the blood $\left(\mathrm{SpO}_{2}\right)$ and heart rate (BPM), the DS18B20 temperature sensor can detect temperatures on the surface of the skin or body. Based on the results of measurements on 3 different respondents with 6 times of data retrieval and compared with standard tools the largest error value obtained from $\mathrm{SpO}_{2}$ is $0.68 \%$ and the smallest error value is $0.17 \%$, while the largest error value from BPM is $0.76 \mathrm{bpm}$ and the smallest error value is 0.42 $\mathrm{bpm}$, the value of skin temperature error obtained is $0.28 \%$ obtained from the measurement of 1 respondent with 6 times of data retrieval and compared with standard tools. The tool is said to be suitable for use because the maximum limit in $\mathrm{SpO}_{2}$ error tolerance is $2 \%$ and $\mathrm{BPM}$ is 5\%. The results of this research can be implemented on infant warmers to improve the monitoring of physiological conditions in patients.
\end{abstract}

INDEX TERM Infant warmer, $\mathrm{SpO}_{2}, \mathrm{BPM}$, Skin Temperature

\section{INTRODUCTION}

There are more than 20 million premature and low weight babies born every year, and $95 \%$ of premature and low weight babies are born in developing countries. There are 3 million babies who die in the first 28 days since birth [1]. After birth, the baby's inner body temperature and skin can drop around $0.1^{\circ} \mathrm{C}-0.3^{\circ} \mathrm{C}$ per minute, from this incident can still be prevented by therapeutic measures using infant warmers as the first treatment after the baby is born [2]. If the nurse does not immediately move the baby to an infant warmer device for therapy or help, the baby will grow up with various diseases or deficiencies such as low IQ, early diabetes, and heart disease. Hypothermia or lack of body temperature below normal is a significant problem that often occurs in newborns [1]. GE Health care manufactures infant warmer equipment, including Panda Warmer and Giraffe Warmer which are placed in the neonatal intensive care unit (NICU) room. This equipment provides a hot effect on the baby without interfering with access to provide care for the baby. Infant warmers can also monitor a baby's health, including body temperature, body weight, $\mathrm{SpO}_{2}$, and pulse [3]. Peter D. Sabota, Austin, TX made a study titled infant warming devices within bed patient support power, signal. control, data, and communications, where the infant warmer device is equipped with temperature control and $\mathrm{SpO}_{2}$ [4]. Stephen Mitchell, Karen P, et al., Made a study entitled newborn respiration monitoring system and method, the infant warmer tool has been equipped with a respiratory monitoring system and $\mathrm{SpO}_{2}$ [5]. Mohamad Ikhsan Dwiyono made a study entitled Non-invasive $\mathrm{SpO}_{2}$ design equipped with an alarm for abnormal diagnosis based on Arduino Atmega 328. The tool only monitors SpO2 but not included BPM and skin temperature [6]. Anggraeni Dara Pratiwi conducted research entitled Infant Incubator Based on Proportional Integral and Derivative (PID) Equipped with Kangaroo Mode on the infant warmer device, had not added 
$\mathrm{SpO}_{2}, \mathrm{BPM}$, and Skin temperature monitoring and there was a weakness in PID response to heater performance due to too little watt heater so the PID response is a little slow [7]. Bayu Wahyudi, Mohamad Miftahudin, and Iqbal Firdaus developed a study entitled Design of Mobile Infant Warmers Using DC Heaters. This tool requires a long heating time, but a low electrical power consumption of 35.6 watts. infant warmer with a DC heater equipped with a battery so that in the event of a power failure by PLN this tool can still be used.[8] Rekha Chandra R, Safeer K P and Srividya P. with the title "Design and Development of Miniaturized Pulse Oximeter for Continuous $\mathrm{SpO}_{2}$ and $\mathrm{HR}$ Monitoring with Wireless Technology Wireless Pulse Process oximeter system for monitoring $\mathrm{SpO}_{2}$ and pulse using PPG techniques. $\mathrm{SpO}_{2}$ and pulse can be measured non-invasively, the value obtained in digital form which is then displayed on a PC via Bluetooth[8]. Harsh Jadav, Amar Bansode and Prof. Divya Sharma conducted a research entitled "PID Temperature Controller Infant Incubator Using RTD" using a PID (Proportional Integral Derivative) temperature control system and PT 100 RTD temperature sensor [9]. IW Aris Wiyadnyana Putra, W. Widhiada and IN Suarnadwipa with the title "PID System for Temperature and Humidity Stability Control for Arduino Microcontroller-Based Baby Incubators" using PID (Proportional Integral Derivative) control, using an LM 35 sensor for temperature measurement and a DHT 22 sensor for measuring Arduino Microcontroller-Based Incubators humidity[10]. Dian Bagus Setyo Budi, Rizal Maulana, and Hurriyatul Fitriyah with the title "Hypoxia Symptom Detection System Based on Oxygen Saturation and Heart Rate Using Arduino Based Fuzzy Methods" monitors $\mathrm{SpO}_{2}$ and BPM using fuzzy methods and data received by the microcontroller is sent via Bluetooth $\mathrm{HC}-05$ and displayed on Android [11]. Tamanna Afrin Tisa, Zinat Ara Nisha, and Md. Adnan Kiber with the title "Design Of An Enhanced Temperature Control System For Neonatal Incubators" using the NTC Thermistor temperature sensor as a temperature detector produced by the incubator [12]. Sumardi, Darjat, Enda Wista Sinuraya, and Rahmat Jati Pamungkas with the title "Design of Temperature Control System for Infant Incubator using Auto Tuning Fuzzy-PI Controller Sumardi1" using Atmega16 as Microcontroller, DHT11 Sensor to detect humidity in infant incubators and Fuzzy-PI control method[13]. Brahmininindya Kanastriloka Receipt with the title "Infant Warmer Equipped with Phototherapy" uses an LM35 temperature sensor as a room temperature controller and a DS18B20 temperature sensor to detect body temperature and is equipped with a phototherapy system [14] Zain-Aldeen S. A. Rahman and Farahan S. A. Hussain "Smart Incubator Based on PID Controller" uses ATmega1280 as a microcontroller, DHT 11 sensor as a bridge detector and NTC sensor to detect temperature. PID (Proportional Integral Derivative) control requires low power [15]. Krishnakanth Balam "Infant Warmer" This equipment is made with a portable system so that newborn babies stay warm during transportation and equipped with Kangaroo Mother Care (KMC). can maintain the WHO recommended temperature of $37^{\circ} \mathrm{C}$ for 4-6 hours, after which it can be reheated [1].
Ramchandran Nair, Santhosh Kumar et al "Infant Warmers Having Integral Backup Warming Blankets" This device also includes the ability to monitor baby's health, including temperature, weight, $\mathrm{SpO}_{2}$, and pulse. Thus, baby warmers provide a warm, comfortable, and supportive development environment for babies [3]. Steven Mitchell, Lawrence Guy, Marjorie Chappelle, and Karen P "Multiple Patient Infant Warming Device, Manager and Method." This tool is already equipped with parameters for patients such as body weight, patient age, patient body size, $\mathrm{SpO}_{2}$, and the value of Apgar examination. [16].

From some of the weaknesses contained in the previous research, the writer wants to develop and complete these deficiencies by making a thesis entitled "Modification of Infant Warmers ( $\mathrm{SpO}_{2}, \mathrm{Bpm}$, and Skin Sensors)" which in this tool has used a DS18B20 sensor to measure skin temperature and does not require a series additionally because the sensor output is digital data, improves patient safety systems and uses low power.

\section{MATERIALS AND METHODS}

\section{A. EXPERIMENTAL SETUP}

This study uses three subjects. Subjects were taken randomlyand data retrieval was repeated 6 times

\section{B. MATERIALS AND DEVICE}

This study uses the MAX30100 sensor to monitor oxygen saturation in the blood $\left(\mathrm{SpO}_{2}\right)$ and heart rate (BPM) and uses a DS18B20 temperature sensor to monitor temperature on the body or skin surface. 2 resistors function as pull-ups before entering the microcontroller. IC Atmega 328 microcontroller is used to process data that has been read by the MAX 30100 sensor and the DS18B20 temperature sensor. 20x4 character $\mathrm{LCD}$ screen as a screen to display values from $\mathrm{SpO}_{2}, \mathrm{BPM}$, and skin sensors. The comparison tool used is the Health-OX Fingertip Pulse Oximeter by Elitech Brand Experiment.

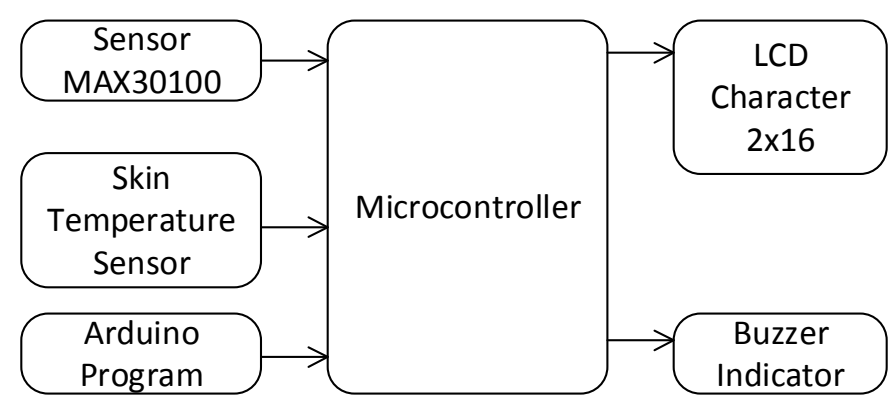

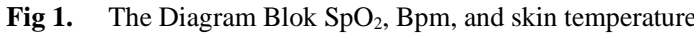

\section{THE DIAGRAM BLOCK}

When the device is activated, the skin temperature sensor and MAX 30100 are attached to the patient, the temperature sensor will read the temperature in the patient's body, the sensor MAX 30100 also reads oxygen saturation in the blood and is passed on to the microcontroller for processing. the output of the sensor readings will be displayed on the display (Fig.1). 


\section{THE FLOWCHART}

When the appliance is activated and the temperature sensor is attached to the patient, the temperature sensor will read the temperature in the patient's body and continue to the microcontroller for processing. The data has been obtained in nominal form and sent on the display to be displayed (Fig. 2)

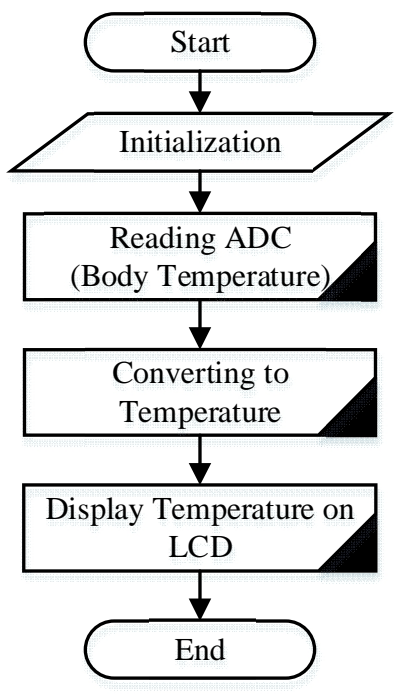

(a)

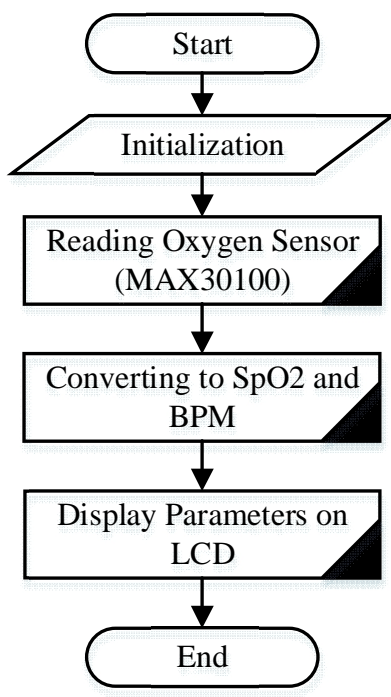

(b)
Fig 2. The flowchart of (a) skin temperature and (b) Sensor MAX 30100

When the device is activated and the MAX 30100 sensor is attached to the patient, the MAX 30100 sensor will read oxygen saturation in the blood $\left(\mathrm{SpO}_{2}\right)$ and heart rate (BPM) and then pass it on to the microcontroller for processing. The data that has been obtained is in the form of a percentage and sent on the display to display (Fig.2).

\section{RESULTS}

\section{A. THE DESIGN}

In this study, the MAX 30100 Sensor and DS18B20 temperature sensors were tested by comparing them with standard measuring devices. The results show (Fig. 3) that the values of the MAX 30100 sensor and the DS18B20 temperature sensor with a standard measuring instrument value are appropriate. In the above program is a program to get the value of the reading results from $\mathrm{SpO}_{2}$ and $\mathrm{Bpm}$ from patients. The program is available in the Arduino MAX-30100 library and is connected to the LCD character. The communication used on the MAX30100 sensor is via the SCL and SCA communication serial at the Arduino Uno ATMega 328 foot. The calculation of pure $\mathrm{SpO}_{2}$ and $\mathrm{Bpm}$ values from the MAX-30100 library by getting results is not much different from the pulse oximetry comparison tool. The pox.update () command is the core of $\mathrm{SpO}_{2}$ and $\mathrm{Bpm}$ output which can then be displayed to the character LCD.

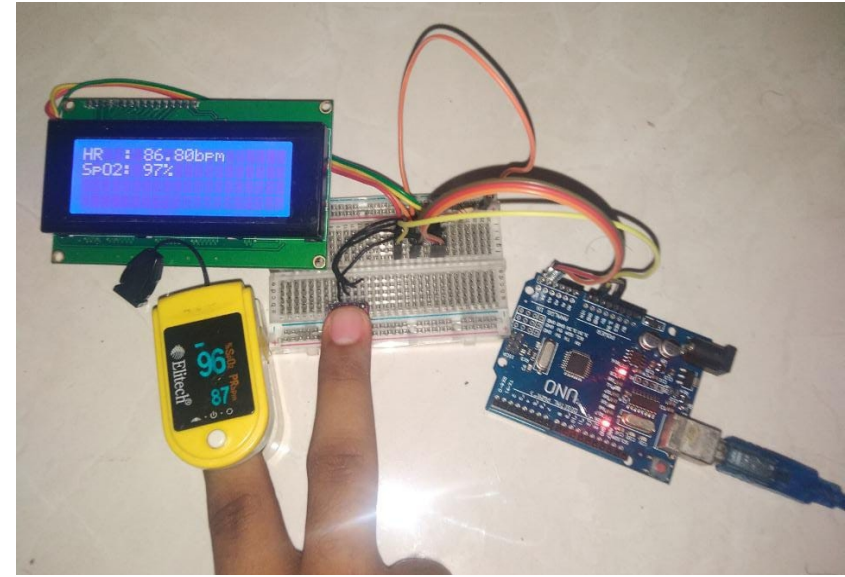

Fig 3. Results of microcontroller circuit design

show response of subject to $\mathrm{SpO}_{2}$ and BPM, respectively. Table I, Table II and Table III show the measurement error for three subjects for $\mathrm{SpO}_{2}, \mathrm{BPM}$, and Temperature sensor respectively

TABLE I.

The error of measurement for the $\mathrm{SpO}_{2}$ parameter between the design and standard unit (Pulse Oximetry)

\begin{tabular}{|c|c|c|c|c|c|}
\hline \multirow{2}{*}{ No } & Tool & Mean & SD & Ua & Error \% \\
\cline { 3 - 5 } & & & & & \\
\hline 1 & Standard & 98,17 & 0,41 & 0,17 & \multirow{2}{*}{0,68} \\
\hline & Design & 97,5 & 0,55 & 0,23 & \\
\hline 2 & Standard. & 96,83 & 0,41 & 0,17 & \multirow{2}{*}{0,17} \\
\hline & Design & 97 & 0 & 0 & \\
\hline 3 & Standard. & 97,83 & 0,55 & 0,23 & \multirow{2}{*}{0,34} \\
\hline & Design & 98 & 0 & 0 & \\
\hline
\end{tabular}

TABLE II.

The error of measurement for the bpm parameter between the design and standard unit (pulse oximetry)

\begin{tabular}{|c|c|c|c|c|c|}
\hline No & Devices & Mean & SD & Ua & Error \% \\
\hline 1 & Standard & 79,5 & 2,81 & 1,15 & \multirow{2}{*}{0,42} \\
\hline & Design & 79,5 & 2,43 & 0,99 & \\
\hline 2 & Standard & 66,67 & 2,73 & 1,11 & \multirow{2}{*}{0,76} \\
\hline & Design & 66,83 & 2,56 & 1,05 & \\
\hline 3 & Standard & 94,5 & 1,52 & 0.62 & \multirow{2}{*}{0,71} \\
\hline & Design & 94,17 & 2,14 & 0,87 & \\
\hline
\end{tabular}

TABLE III.

The error of measurement for the themperature parameter between the design and standard unit (digital thermometer)

\begin{tabular}{|c|c|c|c|c|c|}
\hline No & Devices & Mean & SD & Ua & Error \% \\
\hline 1 & Standard & 36,1 & 0 & 0 & 0,28 \\
\hline & Design & 36,0 & 0 & 0 & \\
\hline
\end{tabular}




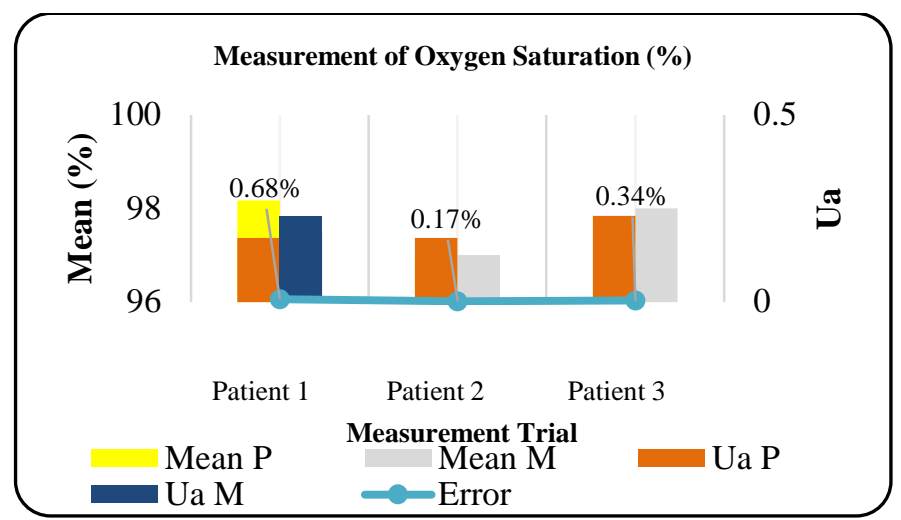

Fig 4. The result of the reading between the comparison with the module $\left(\mathrm{SpO}_{2}\right)$

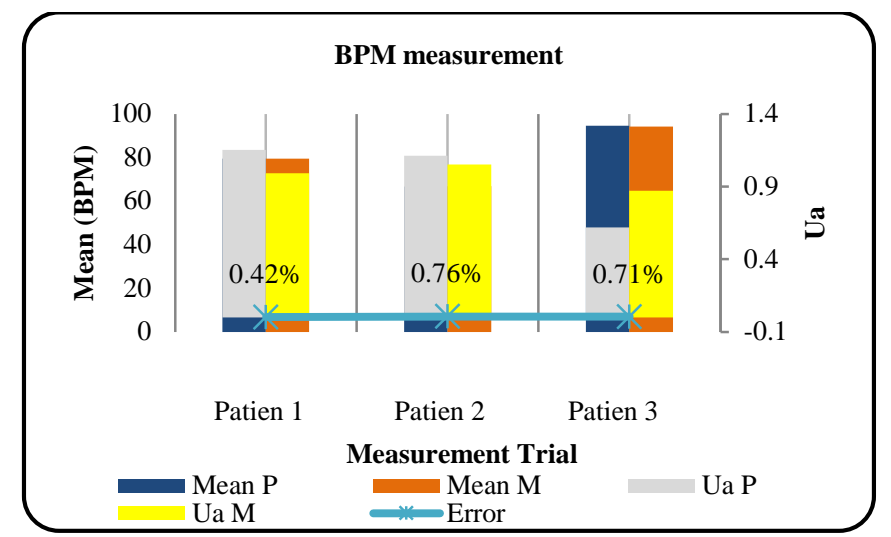

Fig 5. Result of the reading between the comparison with the module (BPM)

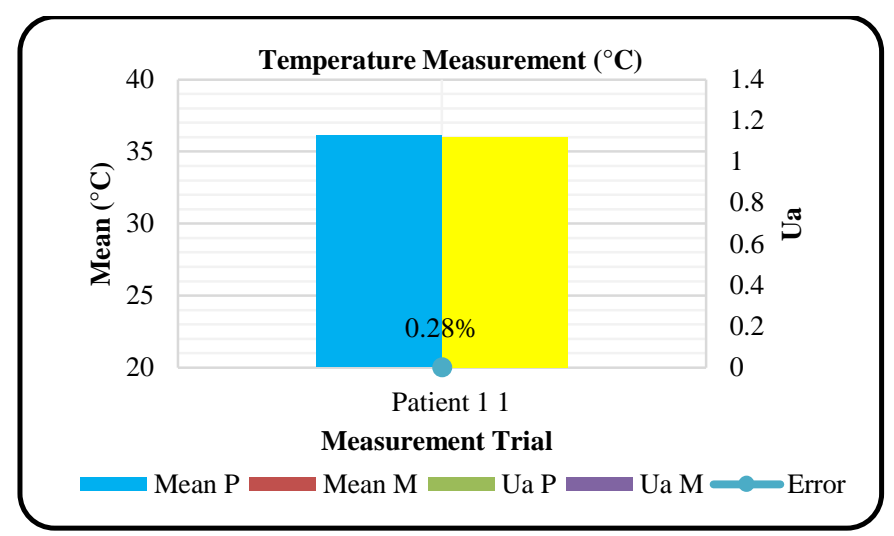

Fig 6. Result of the reading between the comparison with the module (Temperature Skin)

\section{DISCUSSION}

The purpose of this research is to provide a safety system during the therapeutic process using an infant warmer device, which is to develop an infant warmer device that is equipped with a blood saturation monitoring system $\left(\mathrm{SpO}_{2}\right)$, heart rate $(\mathrm{Bpm})$ and temperature of the skin, so that patients can be monitored their health and help users operate infant warmers (Fig. 4, Fig. 5, and Fig. 6). The resulting error value occurs due to differences in the placement of the sensor module with comparators and other interference. Using the right module can reduce the error value obtained from the measurement results. The tool is said to be feasible because the error value obtained does not exceed the maximum tolerance limit.

\section{V.CONCLUSION}

The purpose of this study is to modify the infant warmer tool by adding parameters $\mathrm{SpO}_{2}, \mathrm{BPM}$, and skin sensors Based on the measurement results obtained the greatest $\mathrm{SpO}_{2}$ error value is $0.68 \%$ and the smallest is $0.17 \%$. while the highest BPM error value obtained is $0.76 \mathrm{bpm}$ and the smallest is $0.42 \mathrm{bpm}$. The largest skin temperature error value obtained is $0.28 \%$.

\section{REFERENCES}

[1] Nahimana, E., L. May, A. Gadgil, V. Rapp, H. Magge, M. Kubwimana, A. Nshimyiryo et al. "A low cost, re-usable electricity-free infant warmer: evaluation of safety, effectiveness and feasibility." Public health action 8, no. 4 (2018): 211-217..

[2] E. M. Mccall, F. Alderdice, H. L. Halliday, S. Vohra, and L. Johnston, "Interventions to prevent hypothermia at birth in preterm and/or low birth weight infants," Cochrane Database Syst. Rev., vol. 2018, no. 2, 2018 .

[3] NAIR, Santhosh Kumar RAMCHANDRAN, Harry Edward Belsinger, and Steven Mitchell Falk. "Infant warmers having integral backup warming blanket." U.S. Patent No. 10,966,890. 6 Apr. 2021..

[4] Sabota, Peter D. "Infant warming device with in bed patient support power, signal, control, data, and communications." U.S. Patent 10,709,629, issued July 14, 2020..

[5] AL-Khalidi, Farah Q., Reza Saatchi, Derek Burke, H. Elphick, and Stephen Tan. "Respiration rate monitoring methods: A review." Pediatric pulmonology 46, no. 6 (2011): 523-529.

[6] Zaylaa, Amira J., Mohamad Rashid, Mounir Shaib, and Imad El Majzoub. "A handy preterm infant incubator for providing intensive care: simulation, 3D printed prototype, and evaluation." Journal of healthcare engineering 2018 (2018)..

[7] Khotimah, Khusnul, Muhammad Imam Sudrajat, and Siddiq Wahyu Hidayat. "Infant Incubator Temperature Controlling and Monitoring System by Mobile Phone Based on Arduino." In 2019 International Seminar on Research of Information Technology and Intelligent Systems (ISRITI), pp. 494-498. IEEE, 2019..

[8] Singla, Sunil Kumar, and Varuninder Singh. "Design of a microcontroller based temperature and humidity controller for infant incubator." Journal of Medical Imaging and Health Informatics 5, no. 4 (2015): 704-708..

[9] Singla, Sunil Kumar, and Varuninder Singh. "Design of a microcontroller based temperature and humidity controller for infant incubator." Journal of Medical Imaging and Health Informatics 5, no. 4 (2015): 704-708..

[10] Vaupel, Peter, Michael Höckel, and Arnulf Mayer. "Detection and characterization of tumor hypoxia using pO2 histography." Antioxidants \& redox signaling 9, no. 8 (2007): 1221-1236..

[11] Tisa, Tamanna Afrin, Zinat Ara Nisha, and Md Adnan Kiber. "Design of an enhanced temperature control system for neonatal incubator." Bangladesh Journal of Medical Physics 5, no. 1 (2012): 53$61 .$.

[12] Sinuraya, Enda Wista, and Rahmat Jati Pamungkas. "Design of Temperature Control System for Infant Incubator using Auto Tuning Fuzzy-PI Controller." International Journal of Engineering and Information Systems (IJEAIS) 3, no. 1 (2019)..

[13] Mangan, Shelora, Sara Mosher, and Patricia Scheans. "Challenges to skin-to-skin kangaroo care: cesarean delivery and critically ill NICU patients." Neonatal Network 31, no. 4 (2012): 259-261..

[14] Rahman, Z. S. A., and Farahan SA Hussain. "Smart Incubator Based on PID Controller." Int. Res. J. Eng. Technol 4, no. 3 (2017): 2501-2509.. 
[15] Uwamariya, Josee, Christian Mazimpaka, Leana May, Alphonse Nshimyiryo, Henry A. Feldman, Felix Sayinzoga, Sharon Umutesi et al.

"Safety and effectiveness of a non-electric infant warmer for hypothermia in Rwanda: A cluster-randomized stepped-wedge trial." EClinicalMedicine 34 (2021): 100842. 


\section{APPENDIX}

A. Listing program for Temperature Sensor

sensors.requestTemperatures();

suhu=sensors.getTempCByIndex $(0)$;

lcd.setCursor(0,2);

lcd.print(“Suhu:");

lcd.setCursor(6,2);

lcd.print(suhu);

lcd.setCursor(11,2)

lcd.print("C");

When pin D2 receives data from the sensor in the form of digital data that can be directly displayed on the LCD without having to use additional circuits or be converted again. The temperature is generated at the sensor readings in the form of temperature (Celsius) so that it can be calibrated directly in Celsius. The setting temperature and voltage values at the output can be seen using an oscilloscope.

B. Program of $\mathrm{SpO}_{2}$ and $\mathrm{Bpm}$

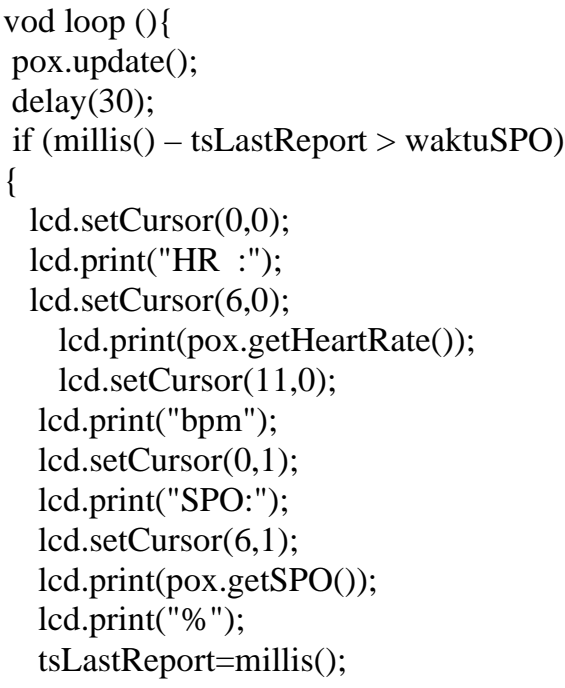

